\title{
Ab Inito exploration of Nanocars as potential corrosion inhibitors
}

\author{
Avni Berisha ${ }^{1,2 *}$ \\ ${ }^{1}$ Department of Chemistry, FNMS, University of Pristina "Hasan Prishtina”, 10000 Pristina, \\ Kosovo \\ ${ }^{2}$ Materials Science-Nanochemistry Research Group, NanoAlb-Unit of Albanian Nanoscience \\ and Nanotechnology, 1000 Tirana, Albania
}

Corresponding author: A.B. avni.berisha@uni-pr.edu.

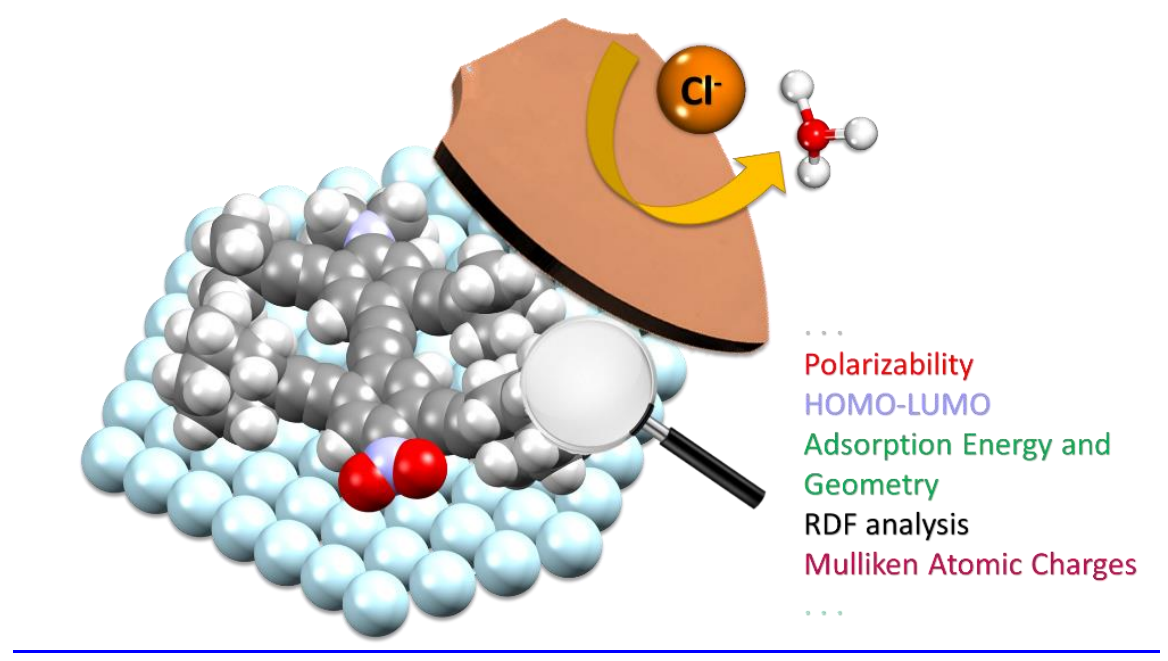

\begin{abstract}
With the intent to search for new unexplored potential inhibitors - a series of newly synthesized NanoCars possessing a permanent dipole moment that makes them able for a controlled surface movements (by electric field gradient from a scanning probe microscopy tip) areis ab initio explored as corrosion inhibitors. The adsorption of the NanoCars onto Fe (lllll 110$)$ surface was assessed using Density Functional Theory (DFT), Monte Carlo simulation (MC), Molecular Dynamics simulation (MD). The acquired results offered molecular level details in relation to the adsorption ability, adsorption centers, geometry and adsorption energetics of NanoCars onto the $\mathrm{Fe}\left(\begin{array}{lll}1 & 1 & 0\end{array}\right)$ interface.
\end{abstract}

Keywords: corrosion, NanoCars, Density Functional Theory, Molecular Dynamics, Monte Carlo 


\section{Introduction}

The interaction of industrial metals such as iron with aggressive environment in the presence of corrosive species like chloride ions and oxygen forms the corrosion products, thereby decreasing the life span of the materials. Corrosion process imposes heavy losses to a number of vital industries [automotive, structural engineering, aerospace, oil and gas (energy), etc.] [1-5]. In order to limit the magnitude of this process the use of corrosion inhibitors remains the simplest and the most efficient approach [1-9]. In this sense a huge portfolio of different molecules are exploited to decrease the corrosion rate of materials. This portfolio includes molecules and materials such as: amino acids[10], triazoles [11], ionic liquids[12], triazines[13], green inhibitor molecules [6][14], polymeric materials [2], purine derivatives[15], quinoxaline derivatives[15], imidazoles [16], quinoline and its derivatives [17], functional and smart coatings [18][19], natural productsplant extracts [20,21], expired drugs[22], nanomaterials [23,24], etc.

To our knowledge there is a lack of studies vis-à-vis the possible exploitation of NanoCars for corrosion protection purposes [25-28]. These mesmerizing molecules were used to organize in 2017 the Nanocar Race [29] - a vastly attention-grabbing scientific event that attracted massive public curiosity [30]. NanoCars are molecular machines capable to transfer efficiently with some kind of control and directionality at the nanoscale level onto metal surface by using an advanced scanning tunnelling microscope [31][30]. In a recently published study by the group of Prof. Tour they reported the synthesis of 4 different newly synthesized NanoCars that own a permanent dipole moment (caused by an $N, N$-dimethyl amino- moiety on one end of the car fixed with a nitro group on the other end) [28]. These NanoCars movement onto surface can be stimulated by the electric field gradient from a scanning probe microscopy tip. In their new design, the NanoCar have the following structural features: tert-butyl wheels, short alkyne chassis, and combination sets of wheels including one set of tert-butyl wheels and another set of larger adamantane wheels on the same car [28]. These molecules are planned to be used in the upcoming second International Nanocar Race (in 2022).

The routine experimental assessments of corrosion using vast number of different techniques: Tafel slope, Electrochemical Impedance Spectroscopy (EIS), Weight loss measurements, Scanning Electron Microscope (SEM), Atomic Force Microscopy (AFM), Scanning ElectroChemical Microscopy (SECM) [2,32-37] . . had given insights regarding the 
electrochemical behavior and kinetics of corrosion process arising at the interface of materials\|corrosive solution and evaluation of the inhibition performance of particular inhibitors and the corrosion rate of materials. Nevertheless, although great details are acquired from such studies, many molecular level insights are only able to be answered through the use of sophisticated and efficient computational simulations based on the use of quantum (Density Functional Theory - DFT) and molecular mechanics (Molecular Dynamics - MD and Monte Carlo - MC). DFT derived parameters such as: molecule polarizability, electron donating energy difference between HOMO and LUMO levels, the fraction of transferred electrons $(\Delta \mathrm{N})$, dipole moment of molecule, energy from inhibitor to metal $\Delta \mathrm{E}$ back-donation have already proven as vital parameters for understanding how and why inhibitors interact with the metal surface in order to exert their corrosion protection ability [38-47]. Moreover, Monte Carlo calculations cooperatively with Molecular Dynamic simulatios are proficient to offer details apropos the adsorption geometry and the adsorption energetics of the molecules onto material surfaces [35-37,48-50].

\section{Calculation details}

\section{DFT calculations}

DFT calculations were realized using the Dmol3 software [51,52]. The geometry optimization (spin unrestricted) using the double numerical plus polarization basis set (DND, Basis file: 3.5 ) [51] in association with the M-11L [53] functional within m-GGA approximation is used [54]. COSMO approach is used to take in the effect of the water as solvent in the calculations $[55,56]$. Self-consistent-field (SCF) convergence criterion was fixed to be less than $1 * 10^{-5} \mathrm{Ha}$. The energy minima were assured by performing a vibrational analysis to test for the nonexistence of imaginary frequencies [57][58].

\section{Monte Carlo and Molecular Dynamic simulation details}

The interaction involving the Fe(110) surface and the Nanocar structures (Figure1) for the Monte Carlo (MC) and Molecular dynamic (MD) simulation, was done using the Fe(110) (under Periodic Boundary Condition) with cell size of: $34.753 \AA$ x $34.753 \AA$ x $10.369 \AA$ with the inclusion of a $40 \AA$ vacuum layer at $\mathrm{C}$ axis containing inside 1500 water molecules/1 NanoCar molecule / 25 hydronium +25 chloride ions. 
The MD is fulfilled under NVT ensemble [59] at $25^{\circ} \mathrm{C}$ via $1 \mathrm{fs}$ time step and a total simulation time of $0.3 \mathrm{~ns}[33,36,42,49,60]$. The temperature control is realized using the Berendsen thermostat MD [5]. The previously prominent COMPASSII force forcefield is used for the simulations MC and MD [61][33,39,40,42,49,62][63]. The whole $300 \mathrm{ps}$ of the MD trajectory is used for the computation of the Radial Distribution Function (RDF) [42,60,62].

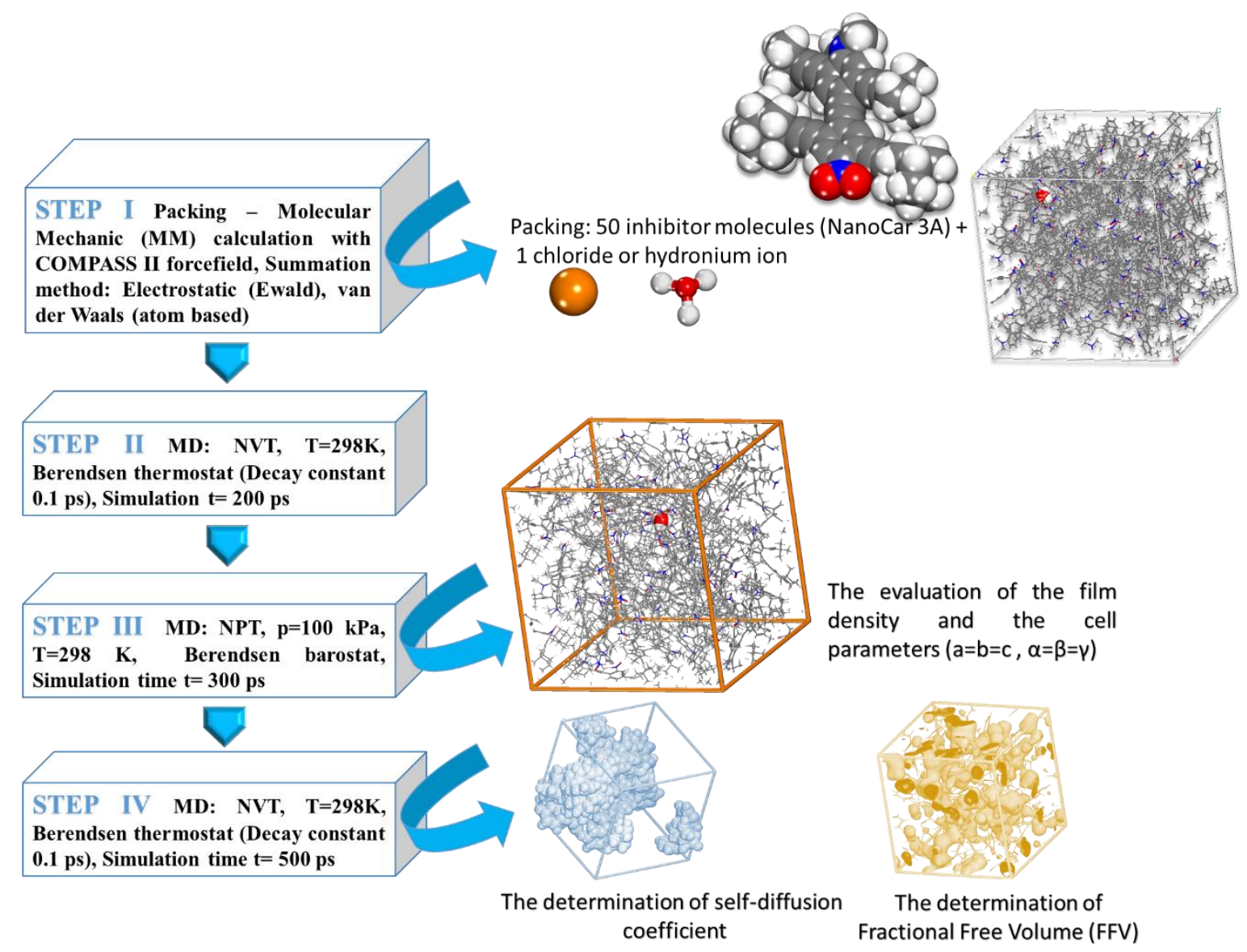

Figure 1. Steps used for the calculation of inhibitor film density, fractional free volume (FFV), and self-diffusion coefficients for the studied NanoCar 3A.

The use of the MD calculations remains as an important path to estimate the diffusion of the corroding species into the formed organic film at the interface of the metal-solution, experimentally this is difficult and yet remains a task to be solved [64][38]. The calculations steps used for the determination of the calculation of the: film density, fractional free volume (FFV), and self-diffusion coefficient of hydronium ion for the NanoCar 3A inhibitor (as a representative structure) film are presented in the Figure 1. 
The Fractional free volume (FFV) of the inhibitor films and the occupied volumes of Connolly surface using the following equation [38]:

$$
F F V=\frac{V_{\text {free }}}{V_{\text {free }}+V_{\text {occupied }}} \quad \ldots \text { Equation } 1
$$

where $\mathrm{V}_{\text {free }}$ is the free volume and $\mathrm{V}_{\text {occupied }}$ is the occupied volume of the PBC box containing the inhibitor film.

The determination of the self-diffusion coefficient (SDC) is calculated by [65] :

$$
D=\frac{1}{6} \lim _{t \rightarrow \infty} \frac{d}{d t} \sum_{i=1}^{N \alpha}\left\langle\left(r_{i}(t)-r_{i}(0)\right)^{2}\right\rangle \quad \ldots \text { Equation } 2
$$

where the $\left\langle\left[\left(r_{-} i(t)-r_{-} i(0)\right)\right]^{\wedge} 2\right\rangle$ is the mean squared displacement values obtained from MD trajectory.

\section{Results}

\section{DFT calculations}

The HOMO and LUMO overall spreading and it's symmetry devise as prominent parameters for arbitrating the activity of a molecule and fathoming the development of chemical reactions $[38,50,66]$.

The HOMO focuses on the parts of the molecule that have a predilection to provide electrons to electrophilic species while the LUMO point to the zones of the molecule with a high susceptibility to accept electrons from nucleophilic species. The frontier MO's shows that in the NanoCar inhibitors [ (Figure 2 vacuum) and (Figure 3 in water)] HOMO is mainly distributed over the entire central part (chassis) of the Nanocar with some minor contributions at the alkynic bonds that link the chassis of the NanoCars with their wheels. 

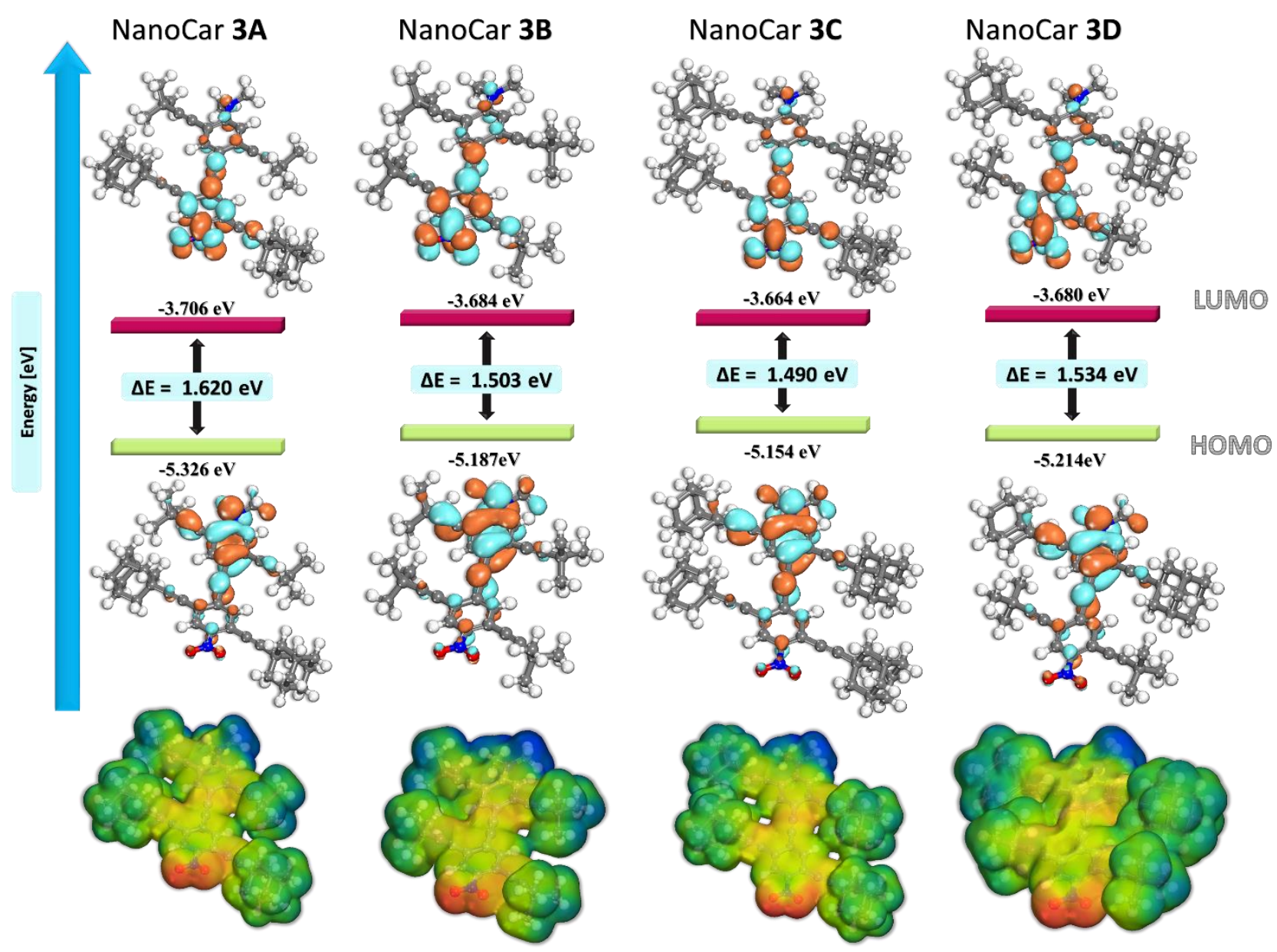

Figure 2. HOMO, LUMO surfaces, and MEP of the NanoCars (in vacuum).

The LUMO density is evenly spread over the chasis structure at the vicinity of the ring containing the N-dimethyl group.. The reasonably significant value of HOMO for NanoCars indicates their aptitude for the interaction with the Fe surface by electron-donation and acceptation as well $[39,45,48,67,68]$. 

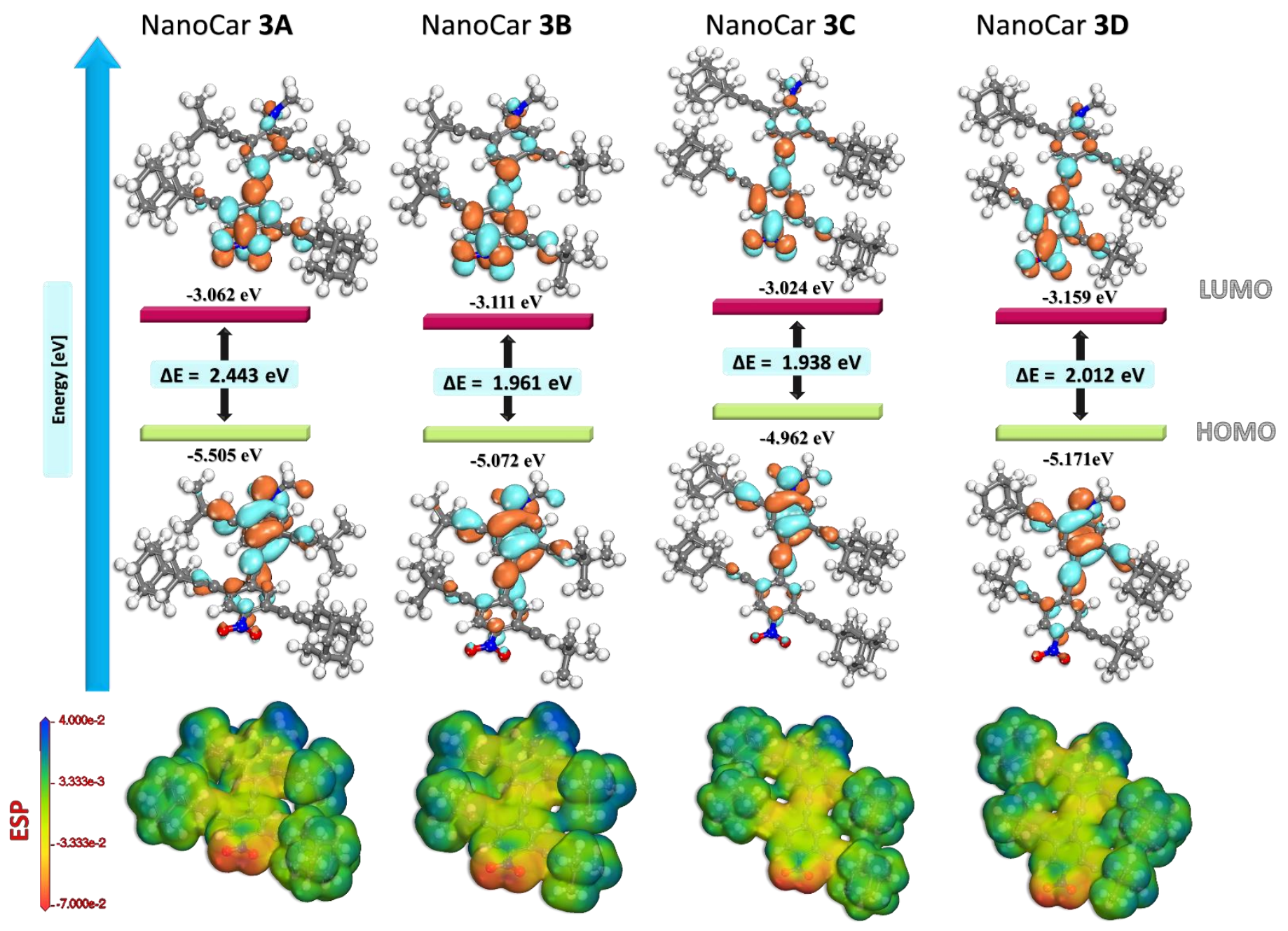

Figure 3. HOMO, LUMO surfaces, and MEP of the NanoCars (in water).

This is reactivity is also evident by inspecting their moderately low electron affinity and high ionization potential values, showing an equal propensity in their electron exchange capacity. Moderately high value of chemical softness (Table 1) and low value of hardness are also expected values that support these inhibitors as relatively high reactive entities with the adsorptive aptitude when they are in the vicinity of the metal surface.

Table 1. Calculated theoretical descriptors for NanoCars inhibitors in vacuum and water.

\begin{tabular}{ccccccccc}
\hline & \multicolumn{4}{c}{ Vacuum } & \multicolumn{4}{c}{ Water } \\
\hline & 3A & 3B & 3C & 3D & 3A & 3B & 3C & 3D \\
HOMO & -5.050 & -5.072 & -4.962 & -5.171 & -5.326 & -5.187 & -5.154 & -5.214 \\
LUMO & -3.062 & -3.111 & -3.024 & -3.159 & -3.706 & -3.684 & -3.664 & -3.680 \\
$\Delta$ E(HOMO-LUMO) & 1.988 & 1.961 & 1.938 & 2.012 & 1.620 & 1.503 & 1.490 & 1.534 \\
\hline
\end{tabular}




\begin{tabular}{crrrrrrrr} 
Ionization energy $(\mathrm{I})$ & 5.050 & 5.072 & 4.962 & 5.171 & 5.326 & 5.187 & 5.154 & 5.214 \\
Electron affinity $\mathrm{A})$ & 3.062 & 3.111 & 3.024 & 3.159 & 3.706 & 3.684 & 3.664 & 3.680 \\
Electronegativity $(\mathrm{X})$ & 4.056 & 4.092 & 3.993 & 4.165 & 4.516 & 4.436 & 4.409 & 4.447 \\
Global hardness $(\eta)$ & 0.994 & 0.981 & 0.969 & 1.006 & 0.810 & 0.752 & 0.745 & 0.767 \\
Chemical potential $(\pi)$ & -4.056 & -4.092 & -3.993 & -4.165 & -4.516 & -4.436 & -4.409 & -4.447 \\
$\quad$ Global softness $(\sigma)$ & 1.006 & 1.020 & 1.032 & 0.994 & 1.235 & 1.331 & 1.342 & 1.304 \\
Global electrophilicity $(\omega)$ & 8.275 & 8.537 & 8.227 & 8.622 & 12.589 & 13.090 & 13.046 & 12.892 \\
Electrodonating $(\omega-)$ power & 10.427 & 10.705 & 10.345 & 10.830 & 14.948 & 15.401 & 15.344 & 15.211 \\
Electroappcepting $(\omega+)$ power & 6.371 & 6.613 & 6.352 & 6.665 & 10.432 & 10.966 & 10.935 & 10.764 \\
$\quad$ Net electrophilicity $(\Delta \omega+-)$ & 6.276 & 6.520 & 6.255 & 6.573 & 10.365 & 10.901 & 10.870 & 10.698 \\
$\quad$ Fraction of transferred & -0.415 & -0.439 & -0.394 & -0.465 & -0.794 & -0.802 & -0.791 & -0.793 \\
$\quad$ electrons $(\Delta N)$ & & & & & & & & \\
Energy from Inhb to Metals & 0.172 & 0.189 & 0.150 & 0.217 & 0.510 & 0.483 & 0.466 & 0.483 \\
$\quad(\Delta N)$ & -0.249 & -0.245 & -0.242 & -0.252 & -0.203 & -0.188 & -0.186 & -0.192 \\
$\quad \Delta$ E back-donation & 8.77 & 8.95 & 8.87 & 8.01 & 12.75 & 15.31 & 15.09 & 14.65 \\
$\quad$ Dipole moment & 746.357 & 623.2294 & 864.8586 & 734.8923 & 1046.45 & 884.43 & 1222.60 & 1031.46 \\
\hline Polarizability $(\alpha)(a . u)$ & & & & & & & &
\end{tabular}

Polarizability is a quantum descriptor related to the distribution and distortion of electron density $[69,70]$. A larger value indicates easiness distribution of the electron density to a metal surface. In our case the polarizability values are relatively high with the maximum value found for the NanoCar 3C structure. 


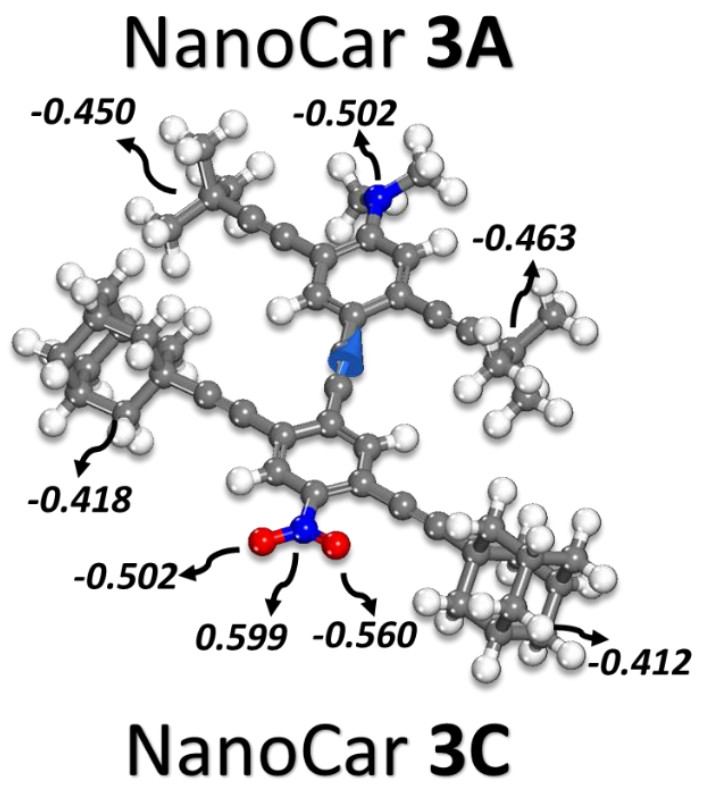

\section{NanoCar 3B}
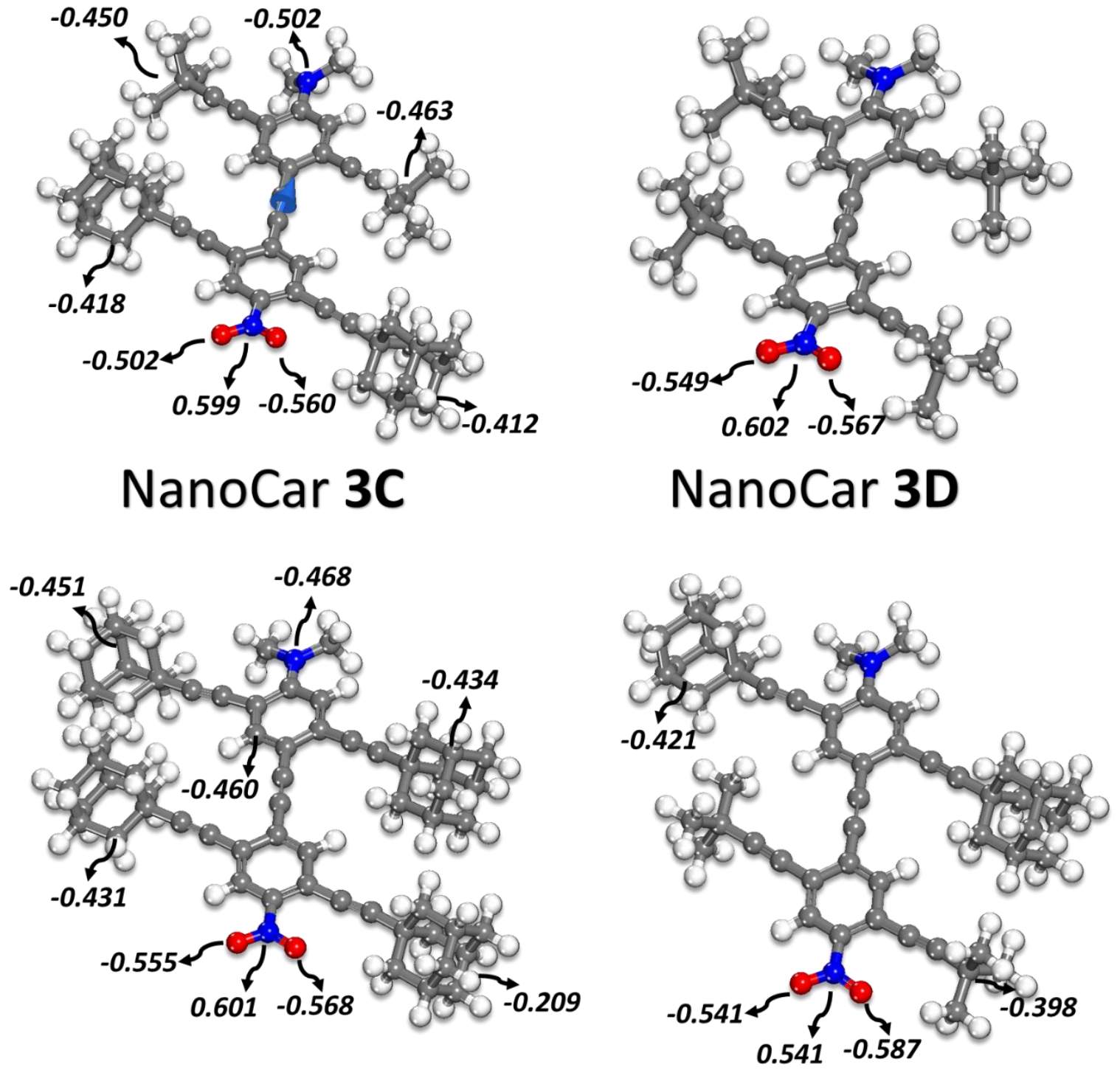

Figure 4. Optimized structures of the NanoCar molecules and their Mulliken atomic charges (MAC).

MAC are trustworthy parameters for indicating the responsible sites (atoms) of the inhibitors that are accountable for the adsorption onto the metals. The interaction between iron surface and the NanoCar molecules is usually well-thought-out to fruitfully take place on the atom with the highest negative charge $[33,45,71]$. The MAC are presented in Figure 4. The maximum negative charges are located on $\mathrm{N}$ and $\mathrm{O}$ atoms, indicating that these centers posses highest electron density and 
interact specifically with the iron surface. This is evident also from Figure $\mathbf{2}$ and Figure $\mathbf{3}$ were the molecular electrostatic potential (MEP) for the inhibitors are shown (area in red).

\section{Monte Carlo and Molecular dynamic simulations}

In the Figure 5 are presented the lowest energy configurations for the NanoCar molecules on the metal surface in the used simulated corrosion media (as chosen above). The adsorption geometries of the inhibitor (as supported by Mulliken charges) indicate that this process is due to the presence of the nitrogen and oxygen atoms. This adsorption conduct is accountable for the foundation of anti-corrosion layer onto the metal surface that protects the material.

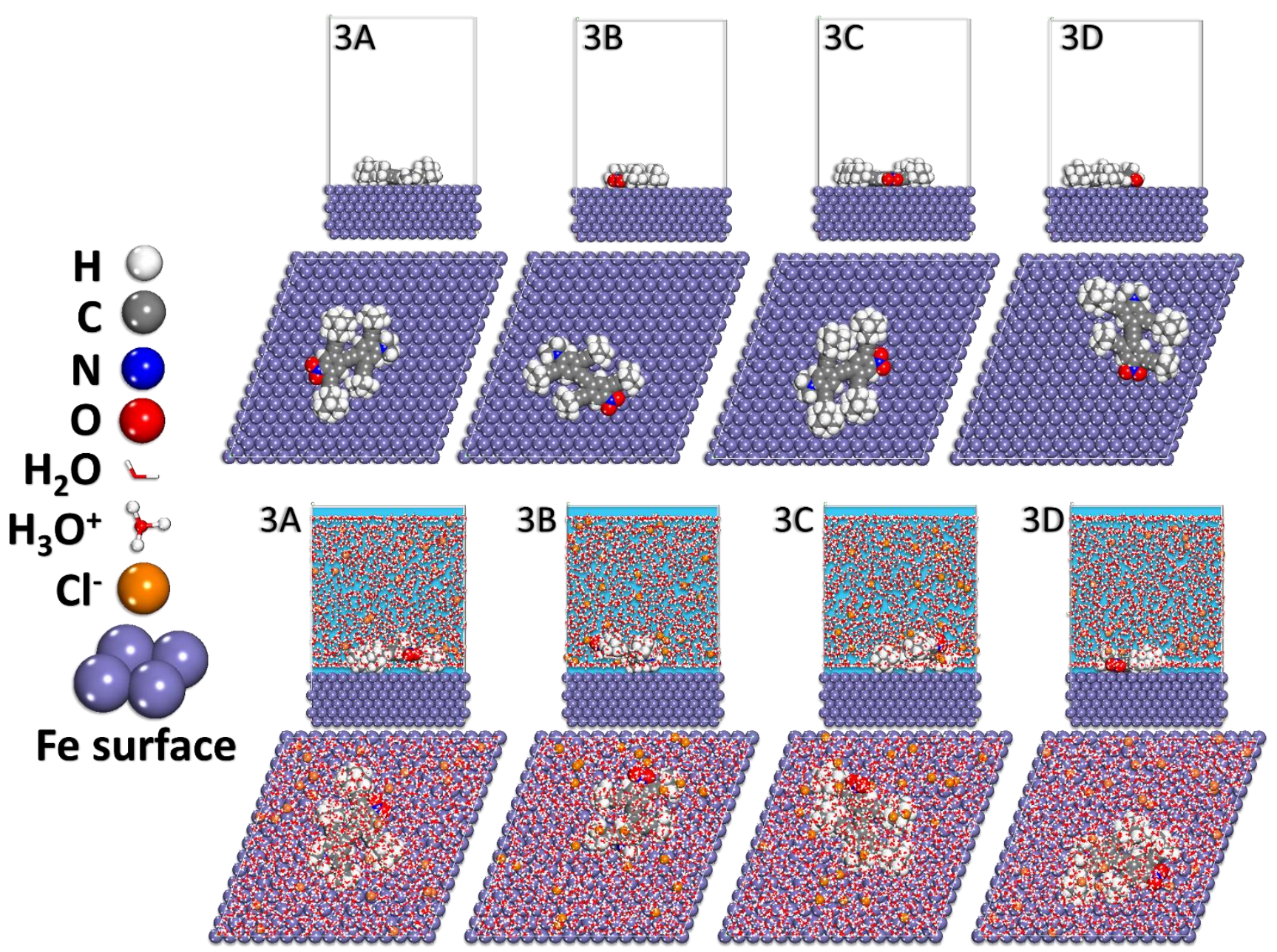

Figure 5. MC poses of the lowest adsorption configurations for the NanoCar inhibitors in the: vacuum and the simulated corrosion media on the iron surface PBC model. 
A way to quantify the extent of the interaction among inhibitor molecules (NanoCar structures) with the iron surface, is fulfilled over the calculation of the adsorption energies using the following equation:

$E_{\text {ads }}=E_{\text {total }}-\left[E_{\text {surface }}+E_{\text {NanoCars }}\right] \quad$ (In vacuum)

$E_{\text {ads }}=E_{\text {total }}-\left[E_{\text {surface }+ \text { water }}+E_{\text {NanoCars }+ \text { surface }}\right]+E_{\text {water }}$ (In the corrosion media)

where: $\mathrm{E}_{\text {total }}$ is the total energy of the system as a result of inhibitor-metal interaction; $\mathrm{E}_{\text {surface }}+$ water and $\mathrm{E}_{\mathrm{NanoCar}+}$ water is system energy in the absence and presence of NanoCar molecules.

The dispersion of the adsorption energies for the enormous amount of adsorptive configurations produced and calculated by the Monte Carlo method for the NanoCar inhibitors is shown in Figure 6.

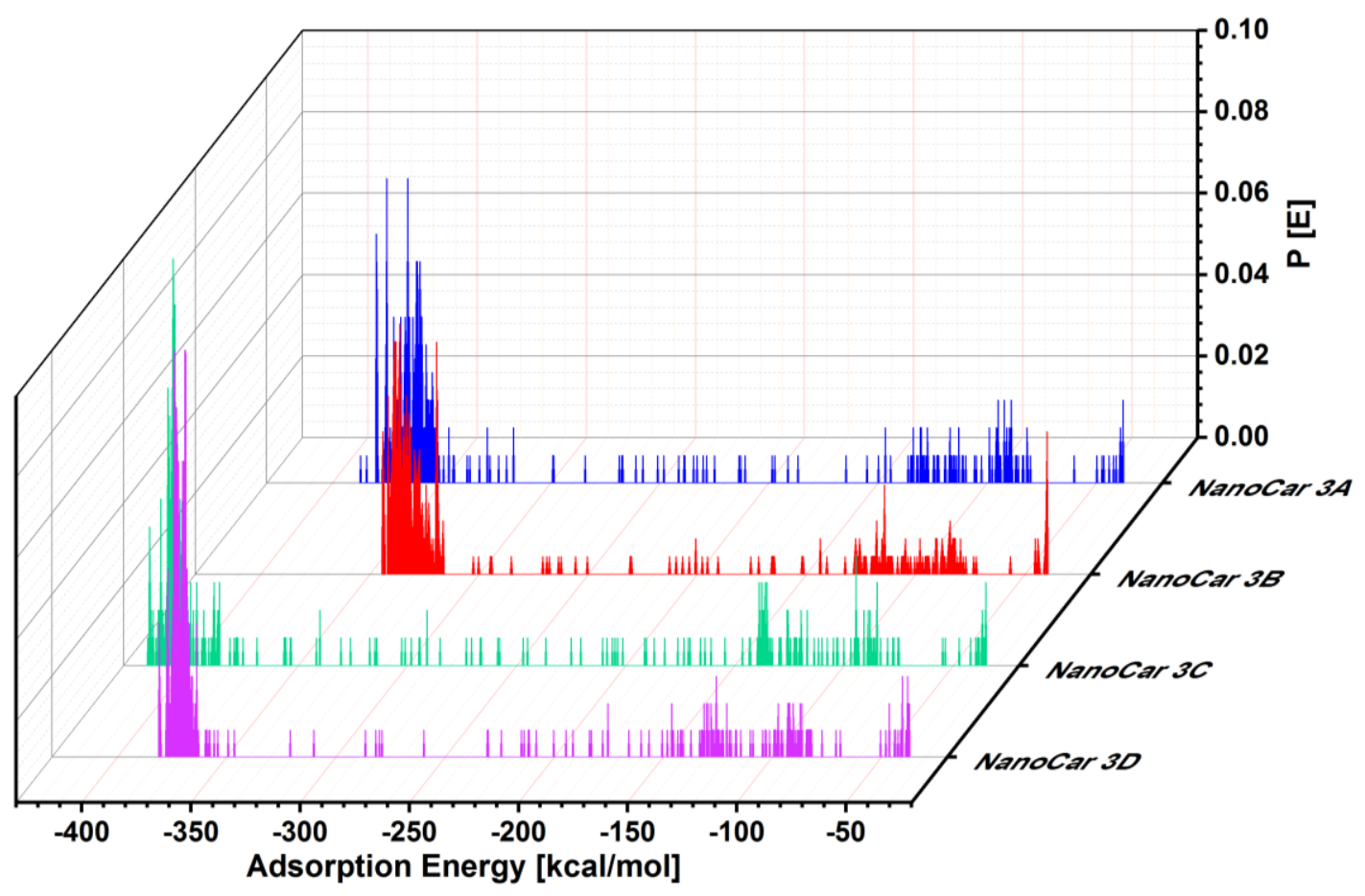

Figure 6. Distribution of adsorption energies for NanoCar inhibitors onto the Fe(110) surface in vacuum.

The Adsorption Energy (Eads) onto Fe(110) surface values for the adsorption of the inhibitors are presented in the Table 2.

Table 2. The distribution adsorption energy values for NanoCars onto the iron surface. 


\begin{tabular}{|c|c|c|c|c|c|c|}
\hline \multirow[b]{2}{*}{ Inhibitor } & \multicolumn{3}{|c|}{ Vacuum } & \multicolumn{3}{|c|}{ Corrosion media } \\
\hline & Min. & Max. & $\begin{array}{c}\text { Max. } \\
\text { probability }\end{array}$ & Min. & Max. & $\begin{array}{c}\text { Max. } \\
\text { probability }\end{array}$ \\
\hline NanoCar 3A & -37.82 & -386.20 & -365.41 & -171.05 & -206.95 & -192.25 \\
\hline NanoCar 3B & -39.94 & -344.02 & -336.31 & -199.85 & -258.27 & -206.55 \\
\hline NanoCar 3C & -35.07 & -417.88 & -407.43 & -340.56 & -416.18 & $-374 . .95$ \\
\hline NanoCar 3D & -37.48 & -381.33 & -381.31 & -201.25 & -243.55 & -220.15 \\
\hline
\end{tabular}

These relatively high adsorption energies (both in vacuum and in simulated corrosion media) point toward a strong interaction of the inhibitors onto the MS surface, leading to an efficient corrosion protection of iron.
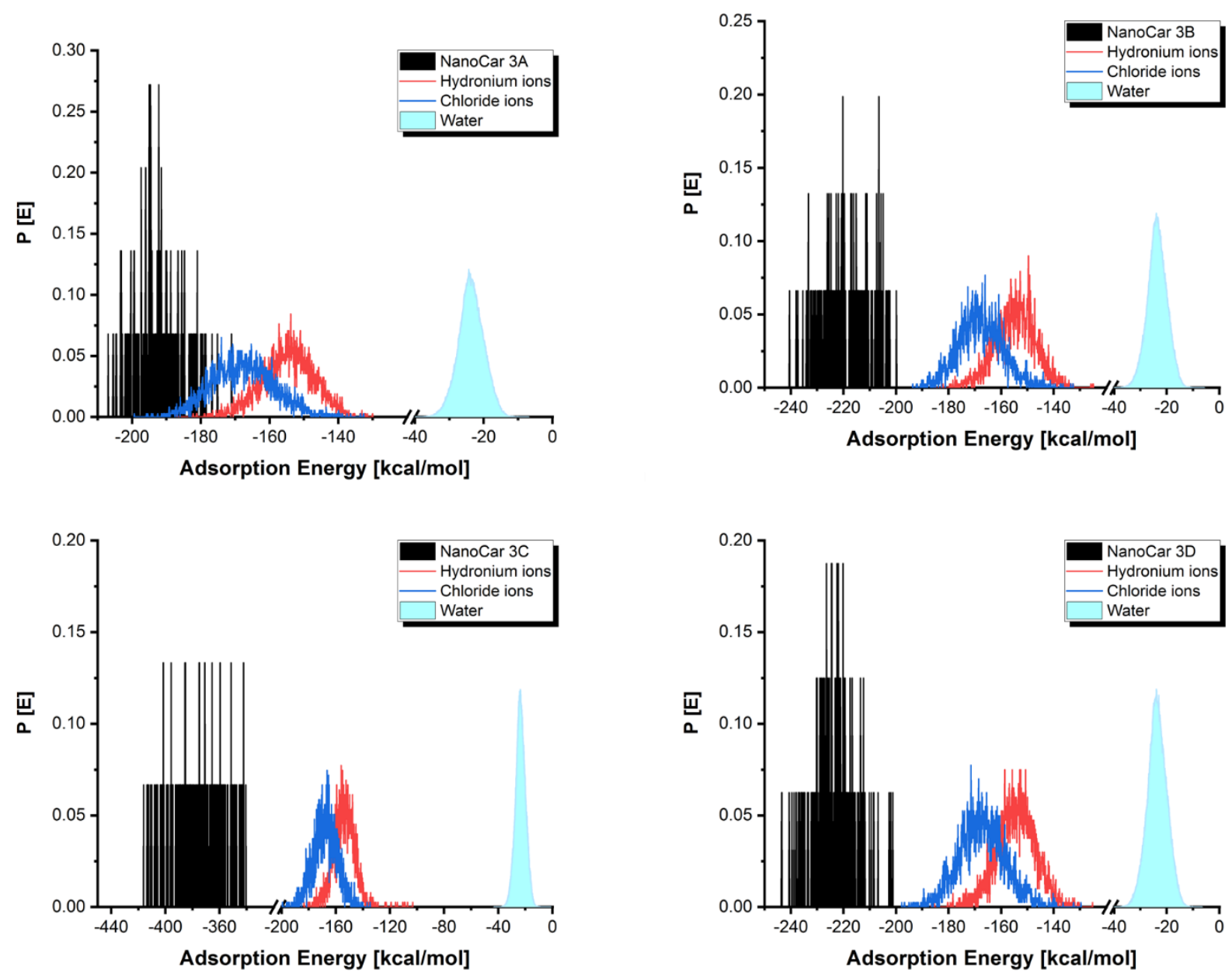
Figure 7. Distribution of adsorption energies for NanoCar inhibitors onto the Fe(110) surface in the presence of the simulated corrosion media.

Both MC and MD calculations show that NanoCars are flat adsorbed onto the iron surface. As seen from Monte Carlo calculations (Figure 7 and Figure 6) the obtained negative values of the adsorption are suggestive of the spontaneity of the adsorption process $[33,40,42,45]$. MD simulations are important as they offer a relatively simple way to trail and capture the dynamics of the adsorption of the studied inhibitors on the metal surface. In the Figure 7 are illustrated the last configurations of inhibitors on iron surface.

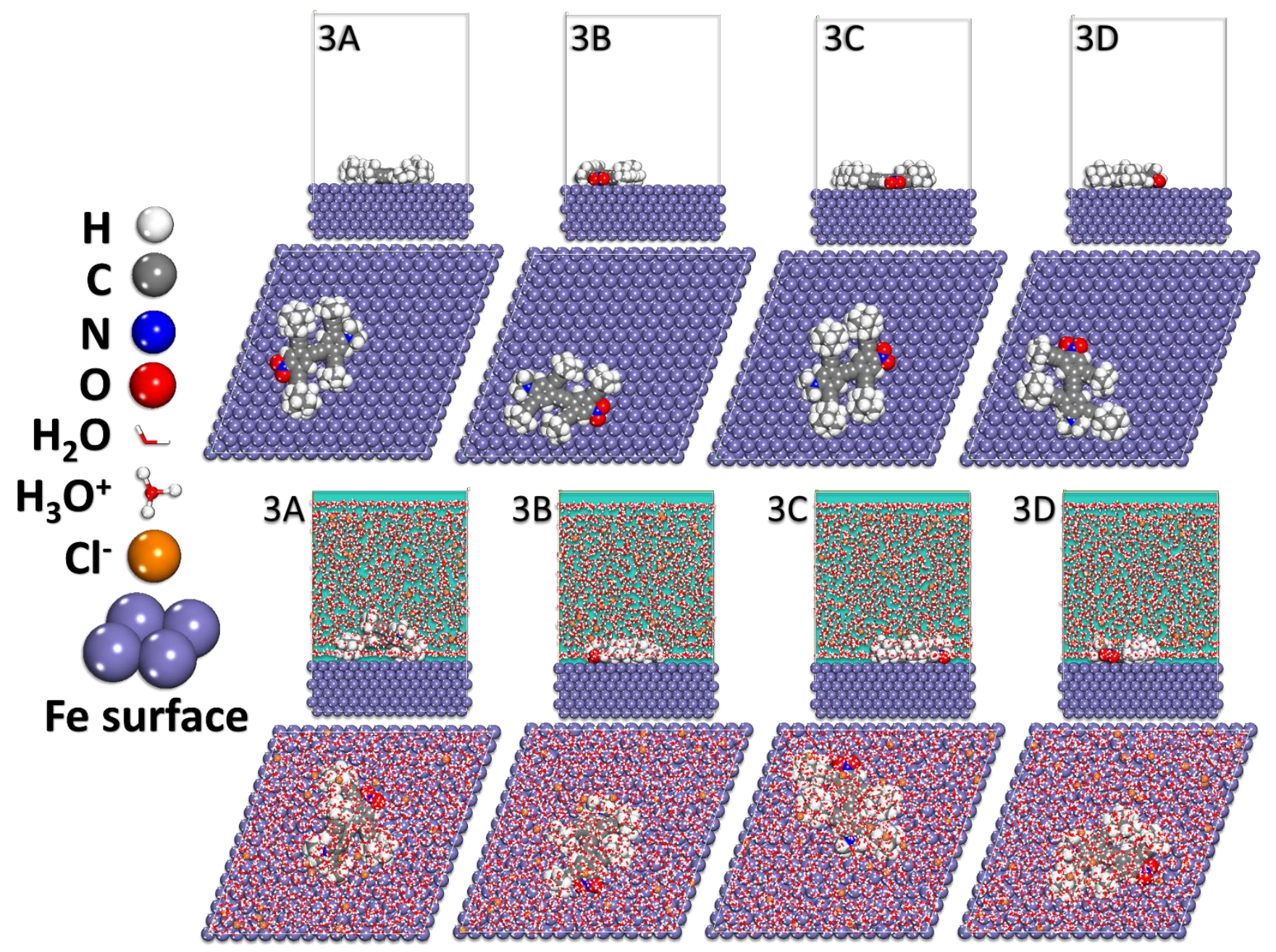

Figure 7. Final MD poses of the lowest adsorption configurations for the NanoCar inhibitors in the: vacuum and the simulated corrosion media on the iron surface PBC model. 

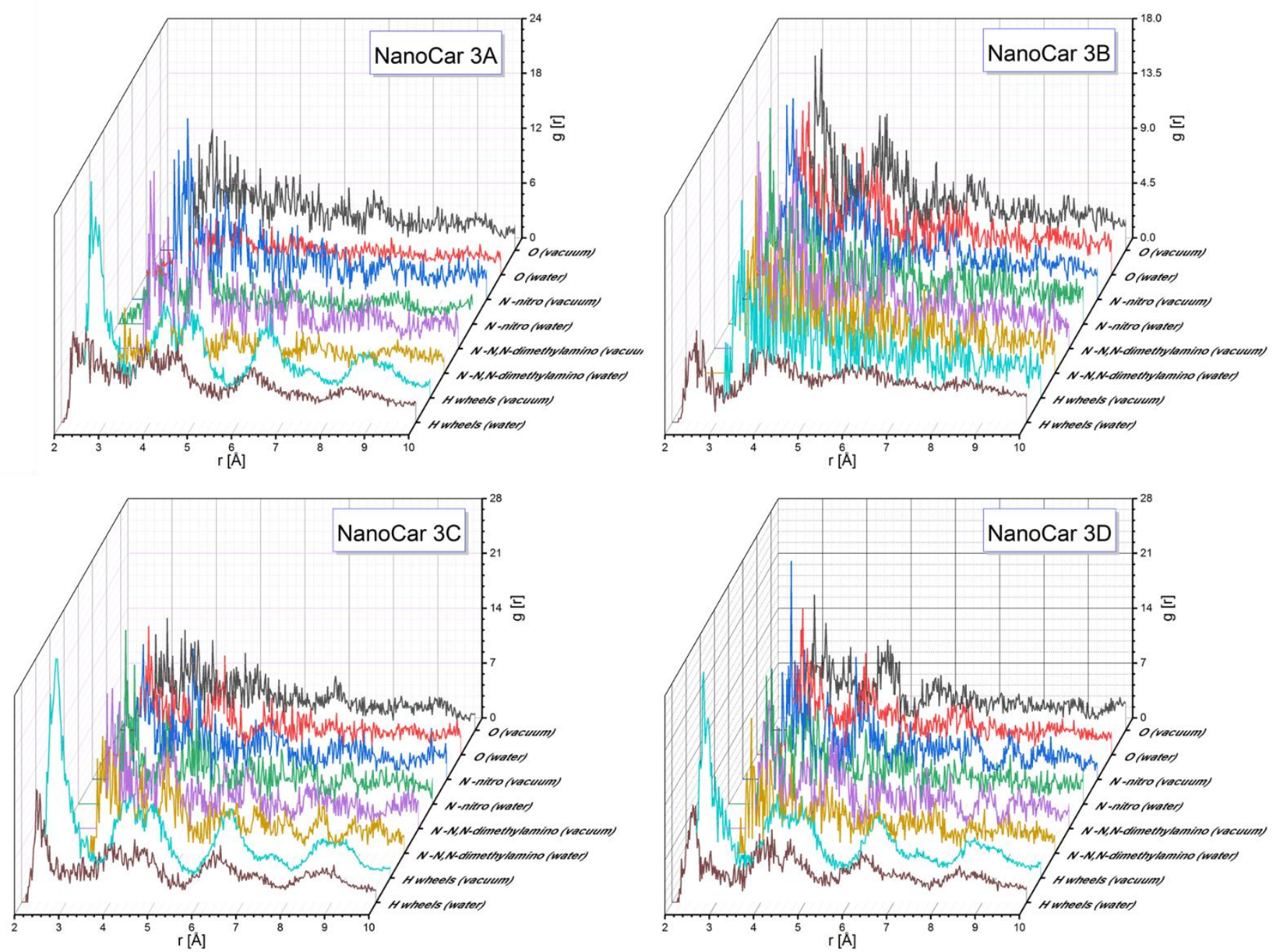

Figure 8. RDF of nitrogen, hydrogen and oxygen atoms of the: NanoCar 3A-3D $\backslash$ onto the iron surface obtained via MD.

It is accepted that the peak presence in the RDF graph at the distance from 1 and $3.5 \AA$ from the surface plane of the metal and the atom of the inhibitor represents a firm confirmation that chemisorption takes place, while for the physisorption process the RDF peaks estimated at larger distances (usually greater than $3.5 \AA$ ) [36,40,42,67,71-73][59]. The RDF of the nitrogen and oxygen atoms (Figure 8) for the NanoCars is under $3.4 \AA$ approving a chemisorption of these molecules on the metal surface. The results from MD and corresponding RDF analysis validate the strong inclination of that these inhibitors adsorb and protect the metal, as they possess exceptional attraction to share/accept electrons with the metal surface $[36,37,62]$. 
The self-diffusion coefficient of the NanoCar 3A film is determined from the slope of the Mean Square Displacement (MSD) (region from 200 - 450 ps) of 5 molecules obtained from MD trajectory (Figure 9) using the Equation 2.

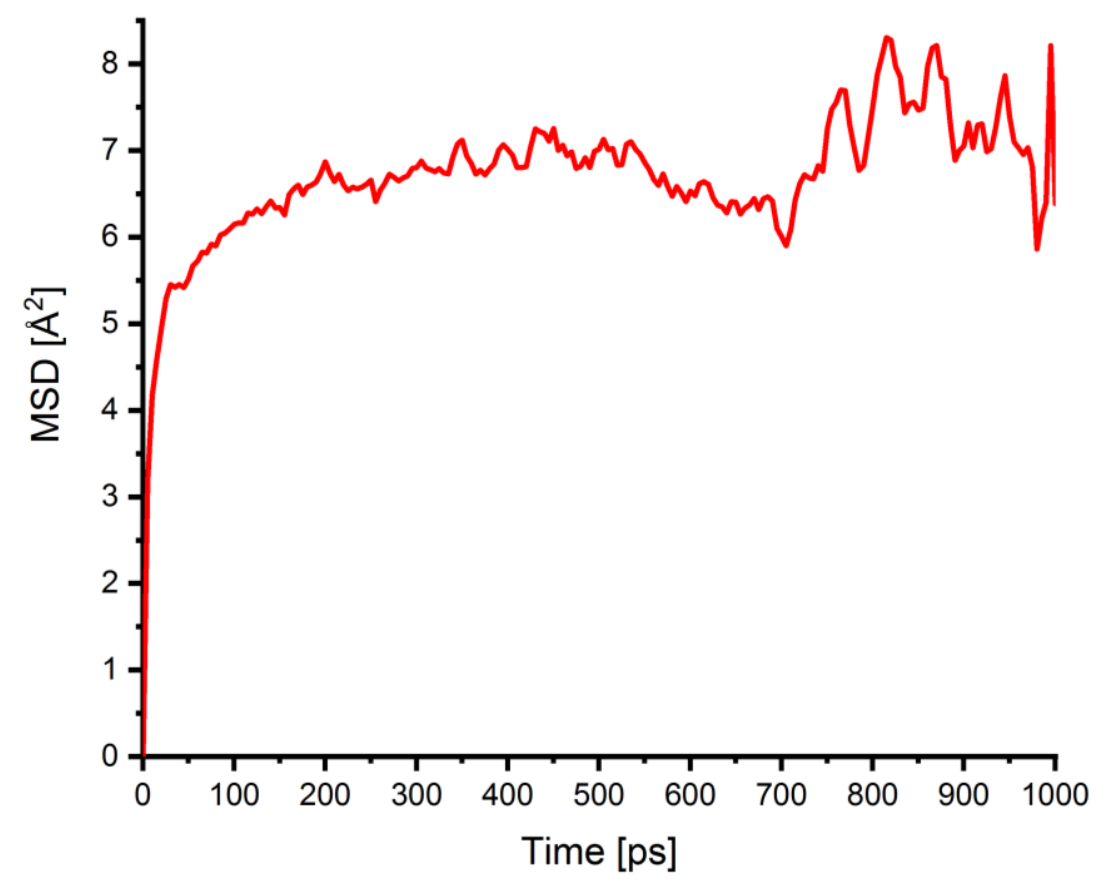

Figure 9. MSD for the NanoCar 3A molecule.

At the frontier of the formed inhibitor film, a factor that impacts the mobility of corrosive ions (hydronium ion) is the mobility of the inhibitor molecules. The film-forming molecules act together and are moved in the corrosive media through the van der Waals force and Coulomb force - in so doing they alter the volume and the shape of the film cavities [38][74][75]. This influences the mobility of corrosive ions into the film. A high mobility film designates a superior diffusion coefficient for the corrosive species. The SDC was foreseen as a measure of the inhibitor film mobility. The inhibitor film composed of the NanoCar 3A has a considerable lower value than well-known inhibitor molecules. This predicts a significant ability of this film to limit the diffusion of the corrosive ions toward the iron surface - thereby reducing the corrosion rate.

Table 3. Calculated values of FFV and self-diffusion coefficient of NanoCar 3A in the modeled inhibitor film in the presence of hydronium ion. 


\begin{tabular}{cc}
\hline Molecule & NanoCar 3A \\
\hline (Self-diffusion coefficient) $\times 10^{-8}\left[\mathrm{~cm}^{2} / \mathrm{s}\right]$ & 3.315 \\
Free volume $\left[\AA^{3}\right]$ & 13088.43 \\
Occupied volume $\left[\AA^{3}\right]$ & 46511.85 \\
FFV & 0.219 \\
\hline
\end{tabular}

As the inhibitor performance is a sum of multiple contributions (volume of the molecule, adsorption ability, adsorption energy, the FFV of the film, the mobility of the film-forming molecules, the interaction of the corrosive species with the film, etc.) - many parameters should be taken into consideration. One of such parameters is the FFV. A higher value of FFV denotes an inhibitor film that possesses voids which permits an enhanced mobility of the corrosive species. For the NanoCar 3A (Table 3), the FFV value is relatively small (0.219) with a low SDC value: $3.315 \times 10^{-8}\left[\mathrm{~cm}^{2} / \mathrm{s}\right]-$ confirming an effective diffusion slowing efficacy of the film.

\section{Conclusion}

This study is focused was carried out using several theoretical methods (DFT, MC and MD) based upon molecular and quantum mechanics. These methods permitted a molecular comprehension on how the NanoCar inhibitors interact with the iron surface to inhibit the corrosion. The computation of the DFT descriptor offered a detailed mean to evaluate why these molecules interact with the surface and the responsible adsorption sites ( $\mathrm{O}$ and $\mathrm{N}$ atoms) responsible for the adsorption process. Monte Carlo and Molecular dynamics calculations showed that these molecules flat-lay onto the iron surface forming spontaneously a barrier film that slows the diffusion of the corrosive species toward the metal surface. The large adsorption energies are supportive of a firm interaction of NanoCars with the iron surface.

\section{Acknowledgments}

The author gratefully acknowledges the support from the Ministry of Education, Science and Technology of Kosovo (Nr.2-5069) for providing the computing resources.

\section{References:}

[1] Verma C, Ebenso EE, Bahadur I, et al. An overview on plant extracts as environmental sustainable and green corrosion inhibitors for metals and alloys in aggressive corrosive media. J. Mol. Liq. Elsevier B.V.; 2018. p. 577-590.

[2] Verma C, Olasunkanmi LO, Akpan ED, et al. Epoxy resins as anticorrosive polymeric 
materials: A review. React. Funct. Polym. Elsevier B.V.; 2020. p. 104741.

[3] Fathima Sabirneeza AA, Geethanjali R, Subhashini S. Polymeric Corrosion Inhibitors for Iron and Its Alloys: A Review [Internet]. Chem. Eng. Commun. Taylor and Francis Ltd.; 2015 [cited 2020 Dec 7]. p. 232-244. Available from: https://www.tandfonline.com/doi/abs/10.1080/00986445.2014.934448.

[4] Hooshmand Zaferani S, Sharifi M, Zaarei D, et al. Application of eco-friendly products as corrosion inhibitors for metals in acid pickling processes - A review. J. Environ. Chem. Eng. Elsevier; 2013. p. 652-657.

[5] Finšgar M, Jackson J. Application of corrosion inhibitors for steels in acidic media for the oil and gas industry: A review. Corros. Sci. Elsevier Ltd; 2014. p. 17-41.

[6] Chaubey N, Savita, Qurashi A, et al. Frontiers and advances in green and sustainable inhibitors for corrosion applications: A critical review. J Mol Liq. 2020;114385.

[7] Raja PB, Ismail M, Ghoreishiamiri S, et al. Reviews on Corrosion Inhibitors: A Short View [Internet]. Chem. Eng. Commun. Taylor and Francis Ltd.; 2016 [cited 2020 Dec 7]. p. 1145-1156. Available from: https://www.tandfonline.com/doi/abs/10.1080/00986445.2016.1172485.

[8] Gece G. Drugs: A review of promising novel corrosion inhibitors. Corros. Sci. Pergamon; 2011. p. 3873-3898.

[9] Tang Z. A review of corrosion inhibitors for rust preventative fluids. Curr. Opin. Solid State Mater. Sci. Elsevier Ltd; 2019. p. 100759.

[10] Hamadi L, Mansouri S, Oulmi K, et al. The use of amino acids as corrosion inhibitors for metals: A review. Egypt. J. Pet. Egyptian Petroleum Research Institute; 2018. p. 11571165.

[11] Phadke Swathi N, Alva VDP, Samshuddin S. A Review on 1,2,4-Triazole Derivatives as Corrosion Inhibitors [Internet]. J. Bio- Tribo-Corrosion. Springer International Publishing; 2017 [cited 2020 Dec 7]. p. 1-12. Available from: https://link.springer.com/article/10.1007/s40735-017-0102-3. 
[12] Verma C, Ebenso EE, Quraishi MA. Ionic liquids as green and sustainable corrosion inhibitors for metals and alloys: An overview. J. Mol. Liq. Elsevier B.V.; 2017. p. 403414.

[13] Chauhan DS, Quraishi MA, Nik WBW, et al. Triazines as a potential class of corrosion inhibitors: Present scenario, challenges and future perspectives. J. Mol. Liq. Elsevier B.V.; 2020. p. 114747.

[14] Wei H, Heidarshenas B, Zhou L, et al. Green inhibitors for steel corrosion in acidic environment: state of art. Mater. Today Sustain. Elsevier Ltd; 2020. p. 100044.

[15] Jiang Z, Li Y, Zhang Q, et al. Purine derivatives as high efficient eco-friendly inhibitors for the corrosion of mild steel in acidic medium: Experimental and theoretical calculations. J Mol Liq [Internet]. 2020 [cited 2020 Dec 7];114809. Available from: https://linkinghub.elsevier.com/retrieve/pii/S0167732220370513.

[16] Mishra A, Aslam J, Verma C, et al. Imidazoles as highly effective heterocyclic corrosion inhibitors for metals and alloys in aqueous electrolytes: A review. J. Taiwan Inst. Chem. Eng. Taiwan Institute of Chemical Engineers; 2020. p. 341-358.

[17] Chauhan DS, Singh P, Quraishi MA. Quinoxaline derivatives as efficient corrosion inhibitors: Current status, challenges and future perspectives. J. Mol. Liq. Elsevier B.V.; 2020. p. 114387.

[18] Montemor MF. Functional and smart coatings for corrosion protection: A review of recent advances. Surf. Coatings Technol. Elsevier; 2014. p. 17-37.

[19] Berisha A, Combellas C, Kanoufi F, et al. Physisorption vs grafting of aryldiazonium salts onto iron: A corrosion study. Electrochim Acta [Internet]. 2011 [cited $2016 \mathrm{Feb}$ 22];56:10762-10766. Available from: http://www.sciencedirect.com/science/article/pii/S0013468611001101.

[20] Raja PB, Sethuraman MG. Natural products as corrosion inhibitor for metals in corrosive media - A review. Mater Lett. 2008;62:113-116.

[21] Mo S, Luo HQ, Li NB. Plant extracts as "green" corrosion inhibitors for steel in sulphuric acid [Internet]. Chem. Pap. De Gruyter Open Ltd; 2016 [cited 2020 Dec 7]. p. 1131-1143. 
Available from: https://link.springer.com/article/10.1515/chempap-2016-0055.

[22] Vaszilcsin N, Ordodi V, Borza A. Corrosion inhibitors from expired drugs. Int J Pharm. 2012;431:241-244.

[23] Jain P, Patidar B, Bhawsar J. Potential of Nanoparticles as a Corrosion Inhibitor: A Review [Internet]. J. Bio- Tribo-Corrosion. Springer; 2020 [cited 2020 Dec 7]. p. 1-12. Available from: https://link.springer.com/article/10.1007/s40735-020-00335-0.

[24] Farag AA. Applications of nanomaterials in corrosion protection coatings and inhibitors [Internet]. Corros. Rev. De Gruyter; 2020 [cited 2020 Dec 7]. p. 67-86. Available from: https://www.degruyter.com/view/journals/corrrev/38/1/article-p67.xml.

[25] Tour JM. Transition to organic materials science. Passive, active, and hybrid nanotechnologies [Internet]. J. Org. Chem. American Chemical Society ; 2007 [cited 2020 Dec 7]. p. 7477-7496. Available from: https://pubs.acs.org/doi/abs/10.1021/jo070543s.

[26] Morin JF, Sasaki T, Shirai Y, et al. Synthetic routes toward carborane-wheeled nanocars. J Org Chem [Internet]. 2007 [cited 2020 Dec 7];72:9481-9490. Available from: https://pubs.acs.org/doi/abs/10.1021/jo701400t.

[27] Jacquot de Rouville H-P, Kammerer C, Rapenne G. From the Synthesis of Nanovehicles to Participation in the First Nanocar Race-View from the French Team. Molecules [Internet]. 2018 [cited 2020 Dec 7];23:612. Available from: http://www.mdpi.com/1420$3049 / 23 / 3 / 612$.

[28] van Venrooy A, García-López V, Li JT, et al. Nanocars with Permanent Dipoles: Preparing for the Second International Nanocar Race. J Org Chem [Internet]. 2020 [cited 2020 Dec 7];85:13644-13654. Available from: https://pubs.acs.org/doi/abs/10.1021/acs.joc.0c01811.

[29] Jacquot de Rouville H-P, Kammerer C, Rapenne G. From the Synthesis of Nanovehicles to Participation in the First Nanocar Race-View from the French Team. Molecules [Internet]. 2018 [cited 2018 Jun 14];23:612. Available from: http://www.mdpi.com/1420$3049 / 23 / 3 / 612$. 
[30] Rapenne G, Joachim C. The first nanocar race. Nat Rev Mater [Internet]. 2017;2:17040. Available from: https://doi.org/10.1038/natrevmats.2017.40.

[31] Castelvecchi D. Drivers gear up for world's first nanocar race [Internet]. Nature. Nature Publishing Group; 2017 [cited 2020 Dec 7]. p. 278-279. Available from: https://pubmed.ncbi.nlm.nih.gov/28426017/.

[32] El Faydy M, Benhiba F, Berisha A, et al. An experimental-coupled empirical investigation on the corrosion inhibitory action of 7-alkyl-8-Hydroxyquinolines on C35E steel in $\mathrm{HCl}$ electrolyte. J Mol Liq. 2020;317.

[33] Hsissou R, Abbout S, Seghiri R, et al. Evaluation of corrosion inhibition performance of phosphorus polymer for carbon steel in [1 M] HCl: Computational studies (DFT, MC and MD simulations). J Mater Res Technol. 2020;

[34] Hsissou R, Dagdag O, Abbout S, et al. Novel derivative epoxy resin TGETET as a corrosion inhibition of E24 carbon steel in $1.0 \mathrm{M} \mathrm{HCl}$ solution. Experimental and computational (DFT and MD simulations) methods. J Mol Liq. 2019;284.

[35] Dagdag O, Berisha A, Safi Z, et al. DGEBA-polyaminoamide as effective anti-corrosive material for 15CDV6 steel in $\mathrm{NaCl}$ medium: Computational and experimental studies. $\mathrm{J}$ Appl Polym Sci [Internet]. 2020 [cited $2020 \mathrm{Feb} 22$ ];137:48402. Available from: https://onlinelibrary.wiley.com/doi/abs/10.1002/app.48402.

[36] Hsissou R, Benhiba F, Abbout S, et al. Trifunctional epoxy polymer as corrosion inhibition material for carbon steel in 1.0 M HCl: MD simulations, DFT and complexation computations. Inorg Chem Commun. 2020;115.

[37] Rbaa M, Dohare P, Berisha A, et al. New Epoxy sugar based glucose derivatives as eco friendly corrosion inhibitors for the carbon steel in $1.0 \mathrm{M} \mathrm{HCl}$ : Experimental and theoretical investigations. J Alloys Compd [Internet]. 2020 [cited 2020 Apr 21];833:154949. Available from: https://linkinghub.elsevier.com/retrieve/pii/S0925838820313128.

[38] Berisha A. Experimental, Monte Carlo and Molecular Dynamic Study on Corrosion Inhibition of Mild Steel by Pyridine Derivatives in Aqueous Perchloric Acid. Electrochem 
[Internet]. 2020 [cited $2020 \mathrm{Jul}$ 4];1:188-199. Available from:

https://www.mdpi.com/2673-3293/1/2/13.

[39] Abbout S, Zouarhi M, Chebabe D, et al. Galactomannan as a new bio-sourced corrosion inhibitor for iron in acidic media. Heliyon. 2020;6.

[40] Hsissou R, Dagdag O, Abbout S, et al. Novel derivative epoxy resin TGETET as a corrosion inhibition of E24 carbon steel in 1.0 M HCl solution. Experimental and computational (DFT and MD simulations) methods. J Mol Liq. 2019;284:182-192.

[41] Mehmeti VV, Berisha AR. Corrosion study of mild steel in aqueous sulfuric acid solution using 4-methyl-4h-1,2,4-triazole-3-thiol and 2-mercaptonicotinic acid-an experimental and theoretical study. Front Chem. 2017;AUG.

[42] Hsissou R, Dagdag O, Abbout S, et al. Novel derivative epoxy resin TGETET as a corrosion inhibition of E24 carbon steel in $1.0 \mathrm{M} \mathrm{HCl}$ solution. Experimental and computational (DFT and MD simulations) methods. J Mol Liq. 2019;284:182-192.

[43] Jessima SJHM, Berisha A, Srikandan SS, et al. Preparation, characterization, and evaluation of corrosion inhibition efficiency of sodium lauryl sulfate modified chitosan for mild steel in the acid pickling process. J Mol Liq [Internet]. 2020 [cited 2020 Sep 26];114382. Available from: https://linkinghub.elsevier.com/retrieve/pii/S0167732220328798.

[44] Rbaa M, Ouakki M, Galai M, et al. Simple preparation and characterization of novel 8Hydroxyquinoline derivatives as effective acid corrosion inhibitor for mild steel: Experimental and theoretical studies. Colloids Surfaces A Physicochem Eng Asp. 2020;602:125094.

[45] Mehmeti V V., Berisha AR. Corrosion study of mild steel in aqueous sulfuric acid solution using 4-methyl-4h-1,2,4-triazole-3-thiol and 2-mercaptonicotinic acid-an experimental and theoretical study. Front Chem [Internet]. 2017 [cited 2020 Apr 9];AUG:61. Available from: http://journal.frontiersin.org/article/10.3389/fchem.2017.00061/full.

[46] Berisha A, Podvorica F, Mehmeti V, et al. Theoretical and experimental studies of the 
corrosion behavior of some thiazole derivatives toward mild steel in sulfuric acid media [Internet]. Maced. J. Chem. Chem. Eng. 2015 [cited 2016 Feb 23]. p. 287-294. Available from: http://www.mjcce.org.mk/index.php/MJCCE/article/view/576.

[47] Abbout S, Zouarhi M, Chebabe D, et al. Galactomannan as a new bio-sourced corrosion inhibitor for iron in acidic media. Heliyon. 2020;6:e03574.

[48] El Arrouji S, Karrouchi K, Berisha A, et al. New pyrazole derivatives as effective corrosion inhibitors on steel-electrolyte interface in $1 \mathrm{M} \mathrm{HCl}$ : Electrochemical, surface morphological (SEM) and computational analysis. Colloids Surfaces A Physicochem Eng Asp. 2020;604:125325.

[49] Dagdag O, Berisha A, Safi Z, et al. DGEBA-polyaminoamide as effective anti-corrosive material for 15CDV6 steel in $\mathrm{NaCl}$ medium: Computational and experimental studies. J Appl Polym Sci [Internet]. 2020 [cited 2020 Apr 9];137:48402. Available from: https://onlinelibrary.wiley.com/doi/abs/10.1002/app.48402.

[50] Berisha A, Podvorica FI, Mehmeti V, et al. Theoretical and experimental studies of the corrosion behavior of some thiazole derivatives toward mild steel in sulfuric acid media. Maced J Chem Chem Eng. 2015;34:287-294.

[51] Delley B. An all-electron numerical method for solving the local density functional for polyatomic molecules. J Chem Phys [Internet]. 1990 [cited 2020 Dec 7];92:508-517. Available from: http://aip.scitation.org/doi/10.1063/1.458452.

[52] Delley B. From molecules to solids with the DMol3 approach. J Chem Phys [Internet]. 2000 [cited 2020 Dec 7];113:7756-7764. Available from: http://aip.scitation.org/doi/10.1063/1.1316015.

[53] Peverati R, Truhlar DG. Performance of the M11 and M11-L density functionals for calculations of electronic excitation energies by adiabatic time-dependent density functional theory. Phys Chem Chem Phys. 2012;

[54] Mardirossian N, Head-Gordon M. Thirty years of density functional theory in computational chemistry: An overview and extensive assessment of 200 density functionals [Internet]. Mol. Phys. Taylor and Francis Ltd.; 2017 [cited 2020 Apr 28]. p. 
2315-2372. Available from:

https://www.tandfonline.com/doi/full/10.1080/00268976.2017.1333644.

[55] Klamt A. The COSMO and COSMO-RS solvation models. Wiley Interdiscip Rev Comput Mol Sci [Internet]. 2018 [cited 2018 Dec 3];8:e1338. Available from: http://doi.wiley.com/10.1002/wcms.1338.

[56] Berisha A. Interactions between the aryldiazonium cations and graphene oxide: A DFT study. J Chem. 2019;2019.

[57] Delley B. Ground-state enthalpies: Evaluation of electronic structure approaches with emphasis on the density functional method. J Phys Chem A [Internet]. 2006 [cited 2020 Nov 18];110:13632-13639. Available from: https://pubs.acs.org/doi/abs/10.1021/jp0653611.

[58] Alija A, Gashi D, Plakaj R, et al. A theoretical and experimental study of the adsorptive removal of hexavalent chromium ions using graphene oxide as an adsorbent. Open Chem [Internet]. 2020 [cited 2020 Nov 18];18:936-942. Available from: https://doi.org/10.1515/chem-2020-0148.

[59] Thaçi V, Hoti R, Berisha A, et al. Corrosion study of copper in aqueous sulfuric acid solution in the presence of (2E,5E)-2,5-dibenzylidenecyclopentanone and (2E,5E)-bis[(4dimethylamino)benzylidene]cyclopentanone: Experimental and theoretical study. Open Chem [Internet]. 2020 [cited 2020 Dec 2];18:1412-1420. Available from: https://doi.org/10.1515/chem-2020-0172.

[60] Dagdag O, Hsissou R, El Harfi A, et al. Fabrication of polymer based epoxy resin as effective anti-corrosive coating for steel: Computational modeling reinforced experimental studies. Surfaces and Interfaces. 2020;18.

[61] Sun H, Jin Z, Yang C, et al. COMPASS II: extended coverage for polymer and drug-like molecule databases. J Mol Model [Internet]. 2016 [cited 2020 Feb 22];22:1-10. Available from: http://www.ncbi.nlm.nih.gov/pubmed/26815034.

[62] Dagdag O, Berisha A, Safi Z, et al. Highly durable macromolecular epoxy resin as anticorrosive coating material for carbon steel in $3 \% \mathrm{NaCl}$ : Computational supported 
experimental studies. J Appl Polym Sci. 2020;

[63] Berisha A. The influence of the grafted aryl groups on the solvation properties of the graphyne and graphdiyne- A MD study. Open Chem. 2019;17:703-710.

[64] Zhang J, Liu J, Yu W, et al. Molecular modeling of the inhibition mechanism of 1-(2aminoethyl)-2-alkyl-imidazoline. Corros Sci. 2010;52:2059-2065.

[65] Yan Y, Wang X, Zhang Y, et al. Molecular dynamics simulation of corrosive species diffusion in imidazoline inhibitor films with different alkyl chain length. Corros Sci. 2013;73:123-129.

[66] Dagdag O, Hsissou R, Berisha A, et al. Polymeric-Based Epoxy Cured with a Polyaminoamide as an Anticorrosive Coating for Aluminum 2024-T3 Surface: Experimental Studies Supported by Computational Modeling. J Bio- Tribo-Corrosion. $2019 ; 5$.

[67] Hsissou R, Benzidia B, Rehioui M, et al. Anticorrosive property of hexafunctional epoxy polymer HGTMDAE for E24 carbon steel corrosion in $1.0 \mathrm{M} \mathrm{HCl}$ : gravimetric, electrochemical, surface morphology and molecular dynamic simulations. Polym Bull. 2019 ;

[68] Rbaa M, Dohare P, Berisha A, et al. New Epoxy sugar based glucose derivatives as eco friendly corrosion inhibitors for the carbon steel in $1.0 \mathrm{M} \mathrm{HCl}$ : Experimental and theoretical investigations. J Alloys Compd [Internet]. 2020 [cited 2020 Apr 13];154949. Available from: https://linkinghub.elsevier.com/retrieve/pii/S0925838820313128.

[69] Ser CT, Žuvela P, Wong MW. Prediction of corrosion inhibition efficiency of pyridines and quinolines on an iron surface using machine learning-powered quantitative structureproperty relationships. Appl Surf Sci. 2020;512:145612.

[70] Uppalapati PK, Berisha A, Velmurugan K, et al. Salen type additives as corrosion mitigtor for Ni-W alloys: Detailed electronic/atomic-scale computational illustration. Int J Quantum Chem [Internet]. 2020 [cited 2020 Dec 29]; Available from: https://onlinelibrary.wiley.com/doi/10.1002/qua.26600.

[71] Jessima SJHM, Berisha A, Srikandan SS, et al. Preparation, characterization, and 
evaluation of corrosion inhibition efficiency of sodium lauryl sulfate modified chitosan for mild steel in the acid pickling process. J Mol Liq. 2020;320.

[72] Dagdag O, Hsissou R, El Harfi A, et al. Epoxy resins and their zinc composites as novel anti-corrosive materials for copper in 3\% sodium chloride solution: Experimental and computational studies. J Mol Liq. 2020;315:113757.

[73] Hsissou R, Abbout S, Berisha A, et al. Experimental, DFT and molecular dynamics simulation on the inhibition performance of the DGDCBA epoxy polymer against the corrosion of the E24 carbon steel in 1.0 M HCl solution. J Mol Struct. 2019;1182:340351.

[74] Yu LJ, Zhang J, Qiao GM, et al. Effect of alkyl chain length on inhibition performance of imidazoline derivatives investigated by molecular dynamics simulation. Mater Corros [Internet]. 2013 [cited 2020 Apr 9];64:225-230. Available from: http://doi.wiley.com/10.1002/maco.201106141.

[75] Hofmann D, Fritz L, Ulbrich J, et al. Detailed-atomistic molecular modeling of small molecule diffusion and solution processes in polymeric membrane materials. Macromol Theory Simulations. 2000;9:293-327. 